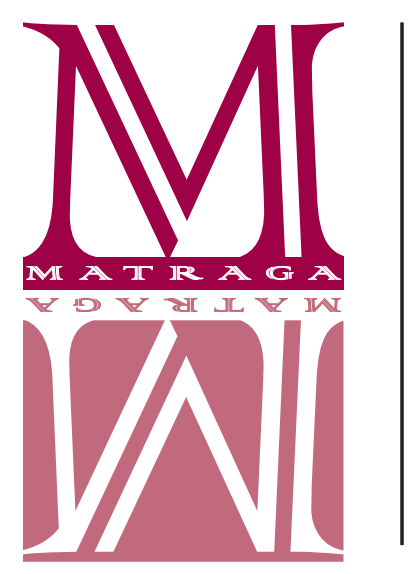

\title{
Velhice, sexualidade e afeto em Diário da guerra do porco, de Adolfo Bioy Casares
}

\author{
Letícia Malloy
}

Universidade Federal de Alfenas

https://orcid.org/0000-0003-2315-4961

\section{RESUMO}

Este artigo objetiva refletir sobre a temática da velhice a partir da análise de Diário da guerra do porco (1969), escrito pelo argentino Adolfo Bioy Casares. Além disso, busca examinar a abordagem conferida a expressões de sexualidade e afeto na idade madura, tomando-se por foco a caracterização de Isidoro Vidal, protagonista do romance. Para tanto, o estudo se vale das perspectivas teóricas de Simone de Beauvoir (2018) acerca da velhice, de Michel Foucault $(1979 ; 1988)$ a respeito da sexualidade e das relações de poder e de Benedictus de Spinoza (2008) sobre a origem e a natureza dos afetos.

PALAVRAS-CHAVE: Velhice; Sexualidade; Afeto; Marginalização do idoso.

\section{Old Age, Sexuality, and Affection in Diário da Guerra do Porco, by Adolfo Bioy Casares}

\section{ABSTRACT}

This article aims at reflecting upon a set of themes pertaining old age by analyzing Diario da guerra do porco (1969), written by the Argentine Adolfo Bioy Casares. Moreover, it seeks to examine the approach adopted towards expressions of sexuality and affection during advancing years, focusing on the characterization of Isidoro Vidal, the novel's protagonist. For such, the study employs the theoretical perspective of Simone de Beauvoir (2018) regarding old age, Michel Foucault's $(1979 ; 1988)$ theses pertaining sexuality and power relations, and Benedictus de Spinoza's (2008) view on the origin and nature of affection.

KEYWORDS: Old age; Sexuality; Affection; Marginalization of the elderly. 


\section{Considerações iniciais}

Estudos dedicados à temática da velhice sob as perspectivas filosófica, sociológica e literária mostram certa convergência ao qualificarem o século XX como um período histórico em que seu contraponto, a juventude, não apenas consiste em recorrente objeto de análise, como também se afigura enquanto polo irradiador de pautas de interesse coletivo (cf. BEAUVOIR, 2018; SECCO, 1994). O ano de 1968 pode ser tomado como ilustrativo dessa tendência, uma vez que concentrou eventos e processos tão emblemáticos quanto a participação estudantil nas reivindicações pela ampliação dos direitos civis à população afro-americana, no posicionamento contrário ao prolongamento da guerra do Vietnã e na resistência ao recrudescimento de regimes políticos na América Latina. A esses movimentos, somam-se a aliança entre estudantes e trabalhadores nos protestos ocorridos em Paris no mês de maio, o apoio às manifestações dos Panteras Negras nos Jogos Olímpicos do México e a Primavera de Praga.

Embora os jovens de 1968 se colocassem firmemente contrários a valores e a encaminhamentos representados por uma velha ordem, o conjunto de reivindicações da juventude não fez tábula rasa das gerações anteriores, reconhecendo, também entre os mais velhos, a voz silenciada do oprimido. Como bem lembra Simone de Beauvoir acerca do estágio inicial da Primavera de Praga, "[n]a Tchecoslováquia, foram os jovens que, a partir de janeiro de 1968, lançaram uma campanha indignada em favor da velhice" (2018, p. 231). A observação de Beauvoir sugere os traços de complexidade a partir dos quais são estabelecidos consensos e dissonâncias entre gerações distintas, bem como desencoraja a correlação estanque entre projetos e dadas faixas etárias. Em 1968, a complexidade das relações intergeracionais foi visitada, também, no campo literário. É deste ano a escrita do romance Diario de la guerra del cerdo - traduzido para o português sob o título de Diário da guerra do porco -, do argentino Adolfo Bioy Casares, que viria a ser publicado em 1969. A seguir, examinam-se abordagens conferidas na narrativa ficcional à senescência, à sexualidade e ao afeto na velhice, levando-se em conta, para isso, os ataques empreendidos contra idosos por uma agremiação de jovens da cidade de Buenos Aires.

\section{Velhice, sexualidade e afeto em Diário da guerra do porco}

Em Diário da guerra do porco, Adolfo Bioy Casares dispõe ao leitor uma cadeia de eventos transcorridos na Buenos Aires da primeira metade do século XX. As relações sociais e as práticas quotidianas engendradas no espaço urbano sofrem abalos: por motivos não explicitados publicamente, jovens portenhos, que se denominam Jovens Turcos, empreendem ataques físicos e intimidações contra idosos, sob a liderança de um demagogo identificado como Arturo Farrell. Em um bairro situado ao norte da capital argentina, seis idosos, amigos de longa data - don Isidro, Jimi, Néstor, Arévalo, Rey e Dante - têm suas vidas afetadas pelas ações do grupo violento. A ameaça à integridade física em decorrência da atitude de um agrupamento de desconhecidos não é, entretanto, o único motivo de apreensão para o grupo de companheiros. Estes, que, a despeito da idade, carinhosamente se denominam muchachos (BIOY CASARES, 2010, p. 7), passam a ser assombrados pela insegurança no espaço privado, nas relações familiares e no 
exercício de atividades até então triviais, como a ida a um estabelecimento comercial com o qual já estavam habituados.

Por um lado, a insegurança experimentada pelas personagens advém das ameaças de violência contra a pessoa idosa; por outro, decorre de dificuldades relativas à definição do que seja o estágio da vida designado pelo rótulo de "velhice" e, por consequência, da ausência de uma categorização precisa que distinga o velho dos demais adultos. Em amplo e pormenorizado estudo sobre a velhice, Simone de Beauvoir aponta as dificuldades de uma tal definição ao observar que a velhice se perfaz tanto mediante a percepção que o outro possui a respeito dos sinais verificados no corpo do idoso quanto a partir de um processo, experimentado pelo próprio idoso, em que este se alterna entre o estranhamento e o reconhecimento de suas mudanças na aparência e nos processos fisiológicos. De acordo com Beauvoir,

(...) esta é uma relação dialética entre meu ser para outrem - tal como ele se define objetivamente - e a consciência que tomo de mim mesma através dele. Em mim, é o outro que é idoso, isto é, aquele que sou para os outros: e esse outro sou eu. Geralmente, nosso ser para outrem é múltiplo como o próprio outrem. (2018, p. 297)

A imprecisão do conceito de velhice contribui para que, em Diário da guerra do porco, a caracterização de algumas personagens ganhe em densidade. Isso ocorre, por exemplo, com Isidoro Vidal - conhecido como don Isidro -, o narrador-protagonista que indaga a respeito da própria velhice e que, ao fazê-lo, oscila entre o lugar da vítima que se reconhece idosa e o do adulto que denuncia a senescência no corpo do outro. Esta oscilação se mostra decisiva para a construção de atitudes sobre o envelhecimento ao longo da narrativa, bem como para a delimitação de comportamentos em face das expressões de sexualidade e afeto da pessoa idosa.

Considere-se, primeiramente, que a percepção de don Isidro sobre a velhice começa a ser construída em sua infância. Ao observar Vigilante, o cão que teve quando criança, Isidoro Vidal cria expectativas em face do comportamento do animal, que deveria calar qualquer expressão de sexualidade em prol da fruição de uma velhice considerada digna e respeitável. Tais expectativas, dirigidas ao velho cachorro, são, em momento posterior, estendidas ao homem idoso. A repugnância à sexualidade na velhice assume para don Isidro proporção tamanha que, em suas lembranças, encontra-se também a imagem de "[...] um velho excitado e bêbado perseguindo com uma grande faca desembainhada a senhora Carmen" (2010, p. 10), antiga moradora do inquilinato onde vive o protagonista. É curioso que a lembrança da perseguição tenha ocorrido mais em razão da repulsa à ideia de um velho estar excitado do que em virtude da potencial violência representada pela faca empunhada. Ao carregar consigo uma avaliação negativa sobre a sexualidade na idade madura, don Isidro oferece solo fértil ao cultivo dos preconceitos expressos por seus potenciais agressores, os Jovens Turcos. Com isso, o protagonista permite que habitem em si, a um só tempo, o idoso vulnerável a censuras e ataques e o algoz que não se mostra disposto a conviver com a senectude de seu semelhante.

Ao chamar para si características próprias do sujeito que reproduz percepções pejorativas sobre a velhice, sem, contudo, possuir a liberalidade de imunizar-se dos inconvenientes causados por aquelas mesmas percepções, don Isidro se desdobra em papeis e toma parte em práticas so- 
ciais por meio das quais o poder é engendrado. A referência a práticas sociais como circunstâncias de exercício do poder não se dá nesta análise ao acaso. Vale-se da perspectiva foucaultiana quanto ao estabelecimento de relações de poder. Ao analisar a tese de Michel Foucault a respeito da microfísica do poder, o professor Roberto Machado assevera que

(...) não existe em Foucault uma teoria geral do poder. O que significa dizer que suas análises não consideram o poder como uma realidade que possua uma natureza, uma essência que ele procuraria definir por suas características universais. Não existe algo unitário e global chamado poder, mas unicamente formas díspares, heterogêneas, em constante transformação. O poder não é um objeto natural, uma coisa; é uma prática social e, como tal, constituída historicamente." (1979, p. X)

Compreende-se então que, sob a óptica de Michel Foucault, o poder não se encontra localizado em uma instância, como o Estado ou as instituições jurídicas; antes, realiza-se em articulações interinstitucionais e intersubjetivas (FOUCAULT, 1979, p. 141). Assumindo-se a premissa de que o poder é verificado no manejo de forças exercidas em âmbito interpessoal, não se reconhece em don Isidro, nos Jovens Turcos ou em qualquer outra instância ou personagem a detenção de "um objeto natural, uma coisa" denominada poder.

No comportamento de don Isidro, identificam-se expressões de poder voltadas, notadamente, à mulher idosa. A reprimenda dirigida pelo protagonista à velhice feminina consubstancia-se em pensamentos de reprovação, olhares de censura e desculpas para o não estabelecimento de relações de solidariedade. Nessa linha de raciocínio, as articulações entre don Isidro e idosas qualificam-se como uma espécie de "relação negativa" (FOUCAULT, 1988, p. 81), isto é, por um silêncio repleto de mensagens de desprezo e rejeição. Sem se dispor ao confronto direto, Vidal coloca seus preconceitos à vista, inicialmente, durante encontro com os muchachos no café de Canning, ocasião em que se depara com uma velha senhora no estabelecimento comercial:

O jornaleiro don Manuel entrou, bebeu no balcão seu copo de vinho tinto, foi embora e, como sempre, deixou a porta entreaberta. Ágil para evitar correntes de ar, Vidal se levantou e a fechou. Ao voltar, no meio do salão, por pouco não trombou com uma mulher velha, magra, extravagante, uma prova viva do que Jimi costuma dizer: "Que imaginação tem a velhice para inventar feiúras!". Vidal virou o rosto e murmurou:

- Velha maldita.

Numa primeira consideração dos fatos, para justificar o ex abrupto, Vidal atribuiu à senhora a lufada que quase lhe afeta os brônquios e pensou que as mulheres não se dispõem a fechar as portas porque se julgam, todas elas, rainhas. Depois ponderou que fora injusto nessa acusação, porque a responsabilidade da porta aberta recaía sobre o pobre jornaleiro. À velha só podia censurar sua velhice." (BIOY CASARES, 2010, p. 12-3)

Ao virar o rosto para imprecar contra a mulher, don Isidro questiona a simples presença da idosa em espaços franqueados ao público, como se àquela não fosse lícito exibir aos demais as marcas deixadas pelo tempo em seu corpo. Em assim procedendo, Vidal oferece sua parcela de contribuição para que a velhice feminina seja relegada a uma sorte de desterro e, por consequência, coopera para o isolamento das mulheres que não deseja ter ao alcance dos olhos. Cabe lembrar, a partir de artigo escrito por Haydée Ribeiro Coelho a respeito de textos de Monique 
Proulx e Clarice Lispector, que o estranhamento é relacionado por Freud àquilo que provoca temor e que "[...] deveria ter permanecido secreto e oculto [sic] mas veio à luz" (FREUD citado por COELHO, 2004, p. 171). Com fundamento na perspectiva freudiana, Haydée Ribeiro Coelho chama a atenção para a impossibilidade de que se mantenham, fora do horizonte de convívio, aspectos e sujeitos tidos como indesejados, já que "[...] o estranho, o estranhamento e o estrangeiro estão imersos no cotidiano, entrelaçados à maneira como os indivíduos se representam, se olham, e, igualmente, são representados" $(2004,185)$.

O estranhamento de don Isidro diante do corpo feminino envelhecido condiciona, também, a maneira como o protagonista se relaciona com Madelón, antiga conhecida e filha do Sr. $\mathrm{Hu}$ berman, morto pelos Jovens Turcos. Ao pensar na mulher, Vidal estabelece uma disjunção entre a Madelón de outrora e a Madelón que tem diante de si, isto é, entre as lembranças da graciosidade da jovem e a imagem de sua maturidade. Na Madelón de tempos idos, o protagonista reconhece a mulher essencial, obliterada pela velha que o tempo esculpiu: "Sempre voltava a acreditar que Madelón era a menina de antes; era só se distrair um pouco e imaginava que aquela menina devia estar escondida em alguma parte e que, se ele se esforçasse, sem dúvida acabaria por encontrá-la" (BIOY CASARES, 2010, p. 23).

Uma das indagações postas por Michel Foucault em A História da Sexualidade relaciona-se às maneiras como o poder interfere nas questões sexuais, produzindo efeitos de "[...] recusa, bloqueio, desqualificação, mas, também, de incitação, de intensificação, em suma, as 'técnicas polimorfas do poder"' (1988, p. 17). Na esteira desse questionamento, ressalta-se o desprestígio conferido por don Isidro à velha Madelón. Não importa a Vidal que a mulher tome conhecimento de sua dentadura e de sua velhice, uma vez que, em sua presença, "[a]briu um sorriso amplo. Cuidava da aparência diante de qualquer mulher, mas abria exceções" (BIOY CASARES, 2010, p. 24). Em contrapartida, ao ter Madelón nos braços, procura traços da moça que conhecera: “Tentou imaginá-la jovem; mas a via e a cheirava tal como ela era agora” (BIOY CASARES, 2010, p. 113). Por fim, don Isidro rechaça aquele corpo de "[...] pele amarelenta e suada, pintas, unhas curtas, recobertas por uma grossa camada de verniz vermelho. Com certo orgulho pensou que Nélida [a jovem por quem se apaixonara] o deixava incapacitado para Madelón" (BIOY CASARES, 2010, p. 112).

Além de se esquivar das expressões de sexualidade e afeto da mulher idosa, Vidal se recusa a estabelecer vínculos de solidariedade com a velhice feminina. A esse respeito, destaca-se o episódio em que, ao lado do amigo Jimi, don Isidro percorre a rua Canning e lá avista um táxi, ocupado pelo motorista, por um delator e por uma senhora que se encontra aos prantos. Diante da cena, o protagonista não ensaia qualquer pensamento de compaixão a respeito do estado aflitivo da idosa, tampouco a encara de modo compreensivo. Evita, assim, acumpliciar-se na situação de potencial vítima e, sobretudo, confirmar-se como velho por meio do reconhecimento de si mesmo nas rugas de outra pessoa. O protagonista de Diário da guerra do porco vira o rosto para a senectude presente no corpo alheio, procurando fugir da sensação de estranhamento motivada pela presença da velhice e adensando o isolamento da velhice feminina.

Levando-se em conta que, como pondera Foucault, os silêncios "[...] são parte integrante das estratégias que apóiam [sic] e atravessam os discursos” (1988, p. 30), é possível compreender que 
a quietude de don Isidro em relação à cena testemunhada está mais próxima da conivência e do desprezo do que de uma intenção de neutralidade. A opção por manter distância das lágrimas da idosa não inflige prejuízo à consciência de Vidal; pelo contrário, o homem se arrepende, em verdade, de ter constatado a devastação e a feiura no velho rosto feminino. É interessante observar que a imagem da mulher chorosa visita don Isidro novamente quando, durante o velório do amigo Néstor, o protagonista cochila e sonha com aquela face. Em âmbito onírico, o semblante da velha senhora é capaz de produzir efeitos tão maléficos quanto os da face da Medusa, pois mirá-lo teria sido o elemento desencadeador da morte de Néstor.

Apenas Dona Dalmacía, uma das moradoras do inquilinato, subsiste relativamente imune ao desprezo sentido por Vidal em relação a mulheres idosas. Embora perceba na velha o "(...) recrudescimento de certa brusquidão inata, o que deu margem, certamente, para que pessoas novas no bairro a apelidassem, carinhosa e zombeteiramente, de Sargentão", don Isidro reconhece que “(...) no amplo coração daquela senhora sobrava lugar, e sua disposição para o trabalho não conhecia limites" (BIOY CASARES, 2010, p. 52).

Viúva, mãe de oito filhos já adultos e responsável pelo sustento de três netas, Dona Dalmacía traz consigo a representação da mulher que se mantém útil às práticas socioeconômicas, o que lhe serve de salvo-conduto para seguir vivendo de modo respeitável. A idosa tem a seu favor, ainda, o aparente abafamento de sua sexualidade após a perda do marido. Dessa maneira, Dona Dalmacía teria se comportado de acordo com os moldes configurados pela "burguesia vitoriana" (FOUCAULT, 1988, p. 9), cujas expectativas reverberam em outros meios sociais e se voltam, ainda conforme assevera Michel Foucault, aos casais heterossexuais, monogâmicos, legítimos e zelosos quanto à "seriedade da função de reproduzir [...] em um espaço utilitário e fecundo: o quarto dos pais. Ao que sobra só resta encobrir-se; o decoro das atitudes esconde os corpos, a decência das palavras limpa os discursos" (1988, p. 9-10).

A rejeição de don Isidro à feminilidade envelhecida possui, como expressão máxima, a breve, mas contundente reflexão feita pelo protagonista diante da mulher que vive com o amigo Dante. Vidal pouco sabe daquela a quem Dante se refere como sua "senhora"; mesmo assim, arma-se de repulsa quando a mulher abre a porta da casa do amigo e, "[...] envolta em panos negros e soltos" (BIOY CASARES, 2010, p. 151), revela a pele coberta de pelos negros e os cabelos esbranquiçados.

Vidal se perguntou se "aquela bruxa" teria sido ou ainda seria (já que na intimidade dos lares ocorrem coisas inimagináveis) a concubina de seu amigo. "Um quadro tão repulsivo, que o melhor seria desejar-lhes uma pronta morte. É claro que se eu chegar a essa idade gozando de tão boa disposição, por delicadeza não vou rechaçar nenhuma mulher. Tudo que me prove que ainda estou vivo se tornará algo precioso." (BIOY CASARES, 2010, p. 152)

O simples pensamento acerca de relações sexuais entre Dante e a mulher que se encontrava à porta da casa provoca asco em don Isidro, já que traz em si uma transgressão da imagem historicamente moldada quanto aos limites de ação do idoso. O raciocínio do protagonista acaba confirmando certa observação feita por Carmen Lúcia Tindó Secco no que toca às expectativas e aos julgamentos relacionados à pessoa idosa. De acordo com Secco, após o processo de indus- 
trialização, procedeu-se a uma reinvenção social da velhice, por meio da qual as imagens dos sujeitos amadurecidos passam a ser, em razoável medida, excluídas dos círculos de produção, [e] pairam, idealizadas, acima da condição humana” (1994, p. 19). Reflexão similar é desenvolvida por Simone de Beauvoir, segundo a qual

[s]e os velhos manifestam os mesmos desejos, os mesmos sentimentos, as mesmas reivindicações que os jovens, eles escandalizam; neles, o amor, o ciúme parecem odiosos ou ridículos, a sexualidade repugnante, a violência irrisória. Devem dar o exemplo de todas as virtudes. Antes de tudo, exige-se deles a serenidade; afirma-se que possuem essa serenidade, o que autoriza o desinteresse por sua infelicidade. A imagem sublimada deles mesmos que lhes é proposta é a do Sábio aureolado de cabelos brancos, rico em experiência e venerável, que domina de muito alto a condição humana; se dela se afastam, caem no outro extremo; a imagem que se opõe à primeira é a do velho louco que caduca e delira e de quem as crianças zombam. De qualquer maneira, por sua virtude ou por sua abjeção, os velhos situam-se fora da humanidade. Pode-se, portanto, sem escrúpulo, recusar-lhes o mínimo julgado necessário para levar uma vida de homem. (2018, p. 9)

O olhar implacável de Vidal não lhe permite esboçar qualquer tentativa de compreensão ou aceitação do corpo da velha, exceto quando o protagonista reflete sobre o próprio processo de envelhecimento. Nesse instante, a compaixão negada à velhice do outro é convertida em uma espécie de generosidade egocêntrica, pois don Isidro cogita a possibilidade de se relacionar com uma mulher idosa não por afeto, mas para sua própria satisfação. Com isso, na passagem referida, o olhar de Vidal se inquieta com o corpo da "senhora", enquanto o olhar do leitor captura um importante elemento constitutivo da caracterização do protagonista: em uma curta meditação, don Isidro revela uma potencial fragilidade em seu agir ético, visto que admite ser lícita a possibilidade de confirmação da própria virilidade por meio da utilização de corpos dos quais, em princípio, jamais se aproximaria.

Importa observar, por outra parte, que certas reflexões e atitudes de Vidal - a exemplo da meditação sobre a "senhora" de Dante - não possuem, como fonte única ou resposta definitiva, um caráter prejudicado por pensamentos ególatras ou por escolhas questionáveis em âmbito ético. Há que se levar em consideração o conflito identitário experimentado por don Isidro ao longo da guerra ao porco, já que a todo momento o personagem ziguezagueia entre os territórios da vida adulta e da velhice. Se tal oscilação mostra níveis de complexidade na configuração do protagonista, também reforça a posição de Vidal como eixo da narrativa, pois ao vacilar entre os domínios do adulto e do velho o protagonista realça a inexistência de lados oponentes no embate entre juventude e senescência. Todos estão igualmente sujeitos aos efeitos do tempo, e no jovem reside o velho que aquele será um dia.

Desse modo, a dualidade que don Isidro leva consigo coloca-o ao lado do agressor, como no caso de seu comportamento diante da mulher idosa, mas também o conduz a momentos de solidariedade, ainda que tímida, em relação ao envelhecimento masculino. É este o caso do episódio em que don Isidro entabula conversa com Antonia e Nélida, que reclamam sobre o comportamento do velho Faber, morador do inquilinato. Este, supostamente, persegue mulheres que, à noite, vão ao banheiro da habitação coletiva. Pouco antes das queixas feitas por Antonia e Nélida, Faber havia relatado a Vidal que precisara passar a noite no banheiro para se 
esconder dos Jovens Turcos. Por isso, é possível que a presença do velho naquelas dependências tenha sido mal interpretada pelas moças. Por um lado, don Isidro prontamente condena a hipotética conduta de Faber, ao afirmar que velhos “(...) que se metem com mulheres jovens dão um triste espetáculo. Repugnante. Vocês têm razão. Toda a razão. Mas se os compararem com um delator, com um traidor, com um assassino..." (BIOY CASARES, 2010, p. 40). Por outro, o protagonista ensaia uma justificativa para relevar a atitude de Faber: "Ele é velho e feio, mas isso é algo que não se pode jogar na cara dele. Ninguém é velho e feio porque quer" (BIOY CASARES, 2010, p. 41).

Ao entremostrar uma defesa para Faber, Vidal advoga, em última análise, a favor de si mesmo. Don Isidro percebe que, como em um jogo de espelhos, o preconceito com o qual condena os gestos do idoso repercute em sua própria experiência de envelhecimento, o que é corroborado pela maneira como o protagonista se coloca diante das manifestações de sexualidade dos muchachos Leandro Rey e Jimi Newman. Durante diálogo encetado com Jimi, don Isidro imagina "(...) Faber à espreita das moças, escondido junto às latrinas", "Rey beijocando as mãos de Tuna, Jimi tarado como um cachorro" (BIOY CASARES, 2010, p. 74). O julgamento de Vidal em relação ao comportamento dos amigos é complementado por Jimi, que compara Rey a "(...) um molusco, tremendo e babando" (BIOY CASARES, 2010, p. 75).

Os símiles e as metáforas construídas a partir de "comparações animalescas", como pontua Javier de Navascués (1995, p. 75) a propósito do romance casareano, acabam por agravar o processo de desqualificação do idoso. Além de comporem imagens tendentes a brutalizar e a desumanizar a senescência, Vidal e Jimi equiparam o sujeito envelhecido a uma caricatura humilhante em um "desfile de máscaras", a um "deficiente" e a um "sem-vergonha" (BIOY CASARES, 2010, p. 74). Jimi faz uso da ironia para lidar com as consequências do tempo; Vidal, a seu turno, experimenta momentos de melancolia, corroborando a resignação pontuada por Simone de Beauvoir no comportamento dos idosos:

Os interesses em jogo nessa luta não são apenas de ordem prática, mas também de ordem moral: queremos que os velhos se conformem à imagem que a sociedade faz deles. Impomos-lhes regras com relação ao vestuário, uma decência de maneiras e um respeito às aparências. É sobretudo no plano sexual que se exerce a repressão. (BEAUVOIR, 2018, p. 230)

O frequente recolhimento de don Isidro em estados melancólicos influencia a maneira como a personagem transita por espaços compartilhados com os demais. No âmbito doméstico, a condenação da senectude inibe o protagonista de atravessar o pátio do inquilinato para ir ao banheiro. Quando é necessário fazê-lo, o protagonista investe sua caminhada de vergonha e de uma presunção de culpa pelo simples fato de ser um homem envelhecido. No espaço público, o constrangimento de Vidal não é menor. Embora ao início do romance expanda sua observação da cidade e demonstre apego às memórias de uma Buenos Aires pretérita com o propósito de resistir às ameaças do presente, pouco a pouco don Isidro modula o alcance de sua vista e de suas intenções para com o outro, especialmente para com mulheres jovens: "Tem que dizer a si mesmo que elas não são para você. Quando olha demais para elas, vira um velho repugnante" (BIOY CASARES, 2010, p. 63). Nota-se, então, nas reflexões e assertivas de Vidal, a adoção de 
práticas qualificadas, em um extremo, pela frustração ocasionada por interditos cristalizados a partir da assunção de valores e de expectativas sociais e, em outro, por anseios de expressão de virilidade. Esse binarismo convive com outro, de ordem temporal: de um lado, verifica-se a frustração ocasionada pela partida de Violeta, mãe de Isidorito, que deixou Vidal para fugir com um paraguaio quando seu filho era ainda pequeno. De outro, percebe-se em don Isidro o desejo remanescente de superar o abandono e se mostrar vitorioso, como no sonho em que "(...) saltava a cavalo íngremes obstáculos, triunfal entre as mulheres” (BIOY CASARES, 2010, p. 34).

Em Diário da guerra do porco, a melancolia e a frustração relacionadas ao envelhecimento do corpo masculino dividem espaço com o desejo de expressão da sexualidade do protagonista. Esse jogo de forças impede que prevaleça, em don Isidro, o comportamento de um sujeito pudico, moldado segundo a tradição vitoriana que, nos dizeres de Foucault, teria encerrado a sexualidade entre as quatro paredes do ambiente privado burguês (1988, disperso). Quanto a este aspecto, Vidal revela certa ousadia e assume atitudes que podem ser tomadas por transgressoras, a exemplo da ocasião em que faz amor com a jovem Nélida, na casa da moça, ciente de haver deixado a porta de entrada aberta.

Para além de um questionamento da influência de valores vitorianos e burgueses, consubstanciado na relativização das fronteiras entre público e privado, aquela sorte de exibição pessoal consiste em exercício de poder no qual a virilidade é ostentada. Assim, ainda que se reconheça o afeto dirigido por don Isidro a Nélida, não se pode fechar os olhos ao fato de que o amor ofertado por uma jovem no período de ataques aos idosos, apesar dos riscos implicados na expressão de tal sentimento, pode trazer desdobramentos vantajosos ao sujeito marginalizado, afigurando-se como modo de subsistir aos dias de conflito e como abrigo para o velho acuado e exausto.

De toda sorte, verifica-se que a articulação entre práticas sexuais e expressões de afeto no romance de Adolfo Bioy Casares impacta significativamente a percepção que o protagonista idoso tem de si mesmo e do espaço por onde transita. Por isso, afiguram-se pertinentes algumas observações sobre tal articulação, compreendida como fator de adensamento da caracterização do personagem central da narrativa. A propósito da ocorrência de encontros e afetos, parece pertinente trazer a esta análise a perspectiva humanista do holandês Benedictus de Spinoza que, na terceira parte de sua Ética, afirma: "Por afeto compreendo as afecções do corpo, pelas quais sua potência de agir é aumentada ou diminuída, estimulada ou refreada, e, ao mesmo tempo, as ideias dessas afecções" (2008, p. 237).

De acordo com o edifício filosófico de Spinoza, todos os sujeitos se compõem de uma substância que lhes é comum e lhes possibilita a existência; porém, cada sujeito pode ser compreendido com um modo particular de pensar e de agir. A partir dos encontros entre os diferentes modos de pensar e de agir, das afecções que tais modos produzem entre si e das ideias construídas com fundamento naquelas afecções, organizam-se modelos representativos que servem ao propósito de mediar as relações entre sujeito e mundo. Ao comentar a perspectiva de Spinoza a respeito da origem e da natureza dos afetos, Marilena Chauí observa que

quanto mais rica e complexa for a experiência corporal (ou o sistema das afecções corporais), tanto mais rica e complexa será a experiência mental, ou seja, tanto mais a mente será capaz de perceber 
e compreender uma pluralidade de coisas, pois, demonstra Espinosa, nada acontece no corpo de que a mente não forme uma imagem ou uma ideia (mesmo que estas sejam confusas, parciais e mutiladas). E quanto mais rica a experiência mental, mais rica e complexa a reflexão, isto é, o conhecimento que a mente terá de si mesma. (CHAUí, 2006, p. 121)

Sob essa perspectiva, pode-se afirmar que a circunstância do envelhecimento impõe a don Isidro um apanhado de indagações, e as tentativas de formulação de respostas passam, necessariamente, pela interação do personagem com outros modos de pensar e de agir, capazes de impactar positiva ou negativamente as imagens que constrói a respeito de seu corpo e de seu lugar na Buenos Aires tomada pelos Jovens Turcos. Em um primeiro momento, o modus vivendi determinado pela agremiação de jovens ocasiona interações das quais Vidal toma parte de maneira passiva, o que acarreta sua submissão à representação derrisória da velhice que lhe fora apresentada desde a infância. Como reação às ameaças dos jovens, o protagonista oscila entre a confirmação do descrédito da velhice e a afirmação da virilidade do corpo envelhecido. Nas ocasiões de confirmação das interpretações pejorativas do processo de envelhecimento, a angústia de Vidal em face do tratamento hostil dispensado aos sujeitos idosos ocorre com tamanha intensidade que, em certa passagem da narrativa, percebe-se a exaustão do protagonista:

Talvez por estar cansado, se abateu. Achou que lhe faltavam forças e ilusões para suportar a vida. A amizade era indiferente; o amor, baixo e desleal - só o ódio se dava com plenitude. Havia se cuidado e continuaria se cuidando dos ataques dos jovens (a esse respeito não cabiam mais dúvidas), mas ao chegar à Calle Paunero imaginou, como uma solução que valia a pena não descartar, sua própria mão, munida de um revólver imaginário, apontando para a têmpora. Essa visão, que decerto não era mais que um jogo de sua angústia momentânea, levou-o a protestar contra tudo, e particularmente contra si mesmo, porque primeiro defendia a qualquer preço o que depois queria destruir. (BIOY CASARES. 2010, p. 111-2)

Por outro lado, a resposta de don Isidro às ameaças contra os velhos por vezes se realiza mediante o estabelecimento de relações com modos menos intolerantes de pensar e agir. Ao início do relacionamento amoroso com a jovem Nélida, don Isidro antevê a possibilidade de redesenhar vínculos e reconfigurar representações de mundo. $\mathrm{O}$ afeto dirigido à moça ora se mostra como fuga das ações opressivas orquestradas pelos mais novos e como mecanismo de escape utilizado face à chegada da velhice, ora como instrumento para intuir outras possibilidades de organização do espaço por onde transita. A partir do pensamento de que "[h]á Nélida” (BIOY CASARES, 2010, p. 161), Vidal se permite adotar uma decisão que, usualmente, não é atribuída à pessoa idosa: a de recomeçar, valendo-se do estabelecimento de novos laços.

Ao visitar Nélida, o protagonista se sente, pela primeira vez no curso da narrativa, em “(...) uma casa de verdade" (BIOY CASARES, 2010, p. 144). A ideia de um lar introduzida pela moça se afigura convidativa, na medida em que acena para don Isidro com a possibilidade de estar em um ambiente distinto daquele quarto do inquilinato, marcado pela significação de toca, que, compartilhada com o arisco filho Isidorito, não era mais que “(...) uma maneira de viver sozinho" (BIOY CASARES, 2010, p. 134). Como contraponto, Vidal leva, para o novo espaço doméstico, inquietações e inseguranças relacionadas à diferença de idade que podem separá-lo 
da jovem. Corroborando representações de mundo que tendem a marginalizar o idoso, don Isidro avalia o risco de que seu desejo de viver com Nélida acabe sendo tomado por ridículo, e que a moça manifeste sua preferência por Martín, o antigo namorado:

Imaginou a situação: sua retirada vergonhosa, a zombaria dos fregueses, enquanto ao fundo o casal se abraçava; cena final de filme, com o vilão (quer dizer, o velho) castigado, a coerente união dos jovens, os acordes enfáticos da orquestra e o aplauso do público. (BIOY CASARES, 2010, p. 151)

Nessa passagem, Adolfo Bioy Casares parece visitar certa faceta da tradição literária, exemplificada pelas obras de Giovanni Boccaccio e Geoffrey Chaucer. Ao apresentarem tipos correspondentes a velhos abastados e desejosos de um relacionamento com esposas ou amantes jovens, Boccaccio e Chaucer conduzem aqueles idosos, majoritariamente, a desfechos que implicam o escárnio e a exposição pública ao ridículo (cf. BEAUVOIR, 2018, p. 150; MACEDO, 2000 , p. 174). Por outro lado, a despeito das periódicas inquietações acerca da (in)compatibilidade entre a velhice e a experiência amorosa com uma jovem, don Isidro se permite divagar sobre a companhia de Nélida, e tem na mulher a promessa de um "[...] talismã contra o desalento" (BIOY CASARES, 2010, p. 179).

A expectativa de que a moça se afigure como uma tábua de salvação em meio aos dias de violência somente é abortada por ocasião do assassinato de Isidorito, filho de Isidoro Vidal. Após a perda do filho em decorrência de uma agressão perpetrada pelos Jovens Turcos, don Isidro assume uma postura relativamente alheia a Nélida, aos muchachos e ao ambiente em que vive, mergulhado que está na experiência do trauma. De qualquer maneira, o afeto de Nélida na vida do protagonista, mesmo após o assassinato de Isidorito, pode ser vista como experiência mitigadora do luto. Como observado por Noemí Ulla, "[o] amor, motivo constante na narrativa de Bioy Casares, desempenha a tarefa de enlace vital que atenua as situações-limite e dá consolo ao pai quando o filho morre atropelado por um caminhão em circunstâncias trágicas" (2005, p. 177, tradução nossa).

\section{Considerações finais}

Em don Isidro, personagem de ambiguidades manifestas, encontra-se o fio condutor do romance publicado por Adolfo Bioy Casares em 1969. Na caracterização do protagonista, utilizam-se aspectos que ultrapassam tanto a pura e simples vitimização do idoso quanto a intenção de um perfeito enquadramento do sujeito nos domínios da velhice, pois Vidal atravessa a "guerra ao porco" perambulando pela embaçada fronteira entre vida adulta e senescência. Amigo dos muchachos, embora deteste a velhice que nestes habita, portador de ligeira e confessa simpatia pelos discursos do demagogo Arturo Farrell e repositório de elevada repulsa ao envelhecimento feminino, don Isidro oferece contributo à configuração da face inimiga, ainda que assim não proceda deliberadamente.

Em sua trajetória titubeante, o protagonista realça a incoerência de uma demarcação de lados criada por uma situação de barbárie que, de antemão, derrotou a todos. Afinal, os jovens que, 
combativos, põem-se na linha de frente das ações de extermínio, acabam implicados em verdadeira quixotada: almejam, em última análise, controlar a condição humana por meio da extirpação de um de seus aspectos inafastáveis. Como bem observa o muchacho Arévalo, "-Nesta guerra os garotos matam de ódio pelo velho que um dia vão ser. Um ódio bastante assustado...” (BIOY CASARES, 2010, p. 100).

\section{REFERÊNCIAS}

BEAUVOIR, Simone de. A velhice. Trad. Maria Helena Franco Martins. 2. ed. Rio de Janeiro: Nova Fronteira, 2018.

BIOY CASARES, Adolfo. Diário da guerra do porco. São Paulo: Cosac Naify, 2010.

CHAUÍ, Marilena. Espinosa: poder e liberdade. In: BORON, Atilio A (org.) Filosofia política moderna. Buenos Aires: Consejo Latinoamericano de Ciencias Sociales - CLACSO; São Paulo: Faculdade de Filosofia, Letras e Ciências Humanas/USP, 2006.

COELHO, Haydée Ribeiro. O estranho, o estranhamento e o estrangeiro em Monique Proulx e Clarice Lispector. Caligrama. Revista de estudos românicos. p. 171-186. vol. 9. Belo Horizonte: Faculdade de Letras da Universidade Federal de Minas Gerais, 2004.

FOUCAULT, Michel. Microfísica do poder. Org. e Trad. Roberto Machado. 13. ed. Rio de Janeiro: Graal, 1979.

FOUCAULT, Michel. História da sexualidade I. A vontade de saber. Trad. Maria Thereza da Costa Albuquerque e J. A. Guilhon Albuquerque. 13. ed. Rio de Janeiro: Graal, 1988.

MACHADO, Roberto. Introdução. Por uma genealogia do poder. In: FOUCAULT. Microfísica do poder. Org. e Trad. Roberto Machado. 13. ed. Rio de Janeiro: Graal, 1979.

MACEDO, José Rivair. Riso, Cultura e Sociedade na Idade Média. São Paulo: UNESP, 2000.

NAVASCUÉS, Javier de. El esperpento controlado. La narrativa de Adolfo Bioy Casares. Navarra: Ediciones Universidad de Navarra, 1995.

SECCO, Carmen Lucia Tindó. Além da idade da razão: longevidade e saber na ficção brasileira. Rio de Janeiro: Graphia, 1994.

SPINOZA, Benedictus de. Ética. Belo Horizonte: Autêntica Editora, 2008.

ULLA, Noemí. De las orillas del Plata. Cuadernos de ensayo. Buenos Aires: Simurg, 2005. 